\title{
Analysis on Relationship between Accurate Poverty Alleviation and Stock Price Collapse Risk from the Perspective of Information Disclosure
}

\author{
Chuan Lin $(\mathbb{D})$ and Haomiao Zhai \\ Research Center for International Business and Economy, Sichuan International Studies University, Chongqing 400030, China \\ Correspondence should be addressed to Haomiao Zhai; zhaihaomiao@sisu.edu.cn
}

Received 15 November 2021; Accepted 27 November 2021; Published 21 December 2021

Academic Editor: Daqing Gong

Copyright (C) 2021 Chuan Lin and Haomiao Zhai. This is an open access article distributed under the Creative Commons Attribution License, which permits unrestricted use, distribution, and reproduction in any medium, provided the original work is properly cited.

\begin{abstract}
Accurate poverty alleviation (APA) is crucial to building a well-off society in an all-round way. Companies and the capital market are implementers of APA. In the context of stock price collapse risk (SPCR), this paper verifies whether the APA by state-owned listed enterprises (SOLEs) could effectively suppress SPCR. Empirical results show that SOLEs engaging in APA and investing heavily in APA have a relatively low SPCR. This conclusion holds after the control of robustness and endogenous factors. Information disclosure system mediates the effect of APA on SPCR. Besides, APA suppresses SPCR more significantly in central state-owned enterprises (SOEs) and public welfare SOEs. Further analysis indicates that good institutional environment, strong poverty alleviation pressure, poverty experience of executives, and model of party organization governance can effectively enhance the influence of APA on SPCR. The research results suggest that SOLEs actively engaging in APA can effectively suppress SPCR by disclosing APA information. This is an organic manifestation of APA effectiveness in the capital market.
\end{abstract}

\section{Introduction}

In recent years, stock price collapse risk (SPCR) has become a hot topic in macroeconomy and microfinance. SPCR often has no signs and explodes in a short time. After outbreak, the risk can spread from market to market and from enterprise to enterprise. As a result, SPCR could jeopardize the interests of listed enterprises and market investors and even induce systematic risks in the capital market, causing harm to the real economy [1]. Stock price collapse occurred occasionally in the Chinese stock market and elsewhere in the world. For example, the COVID-19 pandemic in early 2020, coupled with the falling crude oil prices across the globe, triggered four circuit breakers of the American stock market in ten days. The trading in a dozen of other countries was curbed thereafter, bringing panic to the global financial market.

Despite its short history, the Chinese stock market experienced multiple stock market collapses in less than three decades. In particular, high leverage funding and short selling mechanism kicked off an overall collapse of the stock market in 2015. In the second half of that year, the stock prices plummeted by over $40 \%$ within 52 days. In severe cases, thousands of stocks hit the limit down multiple times. Therefore, it is of great significance to study SPCR and identify the factors suppressing this risk. The relevant results not only help to stabilize market investors by protecting their income, but also enrich the theories and guide the practices of reducing the risks in financial market and enhancing the support of financial market to real economy.

Information is the leading impactor of SPCR $[2,3]$. To control and reduce SPRC reasonably, the key is to suppress the management's information concealment or encourage them to release information in a timely manner. The relevant paths include external audit [4], media attention [5], and corporate social responsibility (CSR) disclosure [6]. Among them, CSR disclosure weakens the information superiority of the management and provides more internal information to market investors, thereby effectively reducing SPCR [7]. 
Since 2016, China has always regarded accurate poverty alleviation (APA) as a major political and economic mission to build China into a strong modern country [8]. In response, the players in China's capital market are competing to contribute to poverty alleviation. In 2016, China Securities Regulatory Commission (CSRC), Shanghai Stock Exchange, and Shenzhen Stock Exchange released multiple opinions and circulars, calling listed enterprises to disclose information about APA. As a result, more and more listed enterprises took the initiative to disclose APA information timely, according to the relevant standards. As an important item of CSR disclosure, APA information has attracted the attention from the capital market and market investors.

APA by listed enterprises is now a hot spot in the literature. For example, Du et al. [9] pointed out that performance, asset size, and ownership are major influencers of corporate APA. Yi et al. [10] suggested that APA behavior helps enterprises improve their values and slash the cost of equity capital, especially for private enterprises and enterprises in eastern and central China. Wang et al. [11] indicated that private enterprise's APA is driven by government subsidy, reduced financing constraint, and tax preference. All these drivers boost the investment efficiency and performance of enterprises engaging in APA. Ren and Wang [12] held that the enterprises in an industry closely correlated with consumers would actively participate in APA; the willingness to engage in APA increases with the degree of diversity of the enterprise. Chang et al. [13] found that more than $20 \%$ of Chinese listed enterprises were involved in this round of APA, and the executives eyeing political promotion were particularly enthusiastic about implementing APA. Nevertheless, there is no empirical evidence on how APA influences the performance of listed enterprises in the capital market.

How does APA affect corporate performance in the capital market? In theory, there are three possible effects. Firstly, the regulatory authorities have strict requirements on APA information disclosure by listed enterprises. Hence, the listed enterprises engaging in APA would release more information than those not involved in APA. Market investors would acquire relatively rich information about these listed enterprises. Second, the regulatory requirements on APA information disclosure promote the listed enterprises engaging in APA to disclose information timelier, more completely, and more precisely, which contribute to the quality of information disclosure. Thirdly, APA, as a manifestation of good CSR, improves corporate reputation via the information disclosure to the society and the capital market. If a listed enterprise has implemented APA, more information will be released to the capital market, and the enterprise will win the recognition of more market investors. Then, it would be less likely for market investors to vote by foot. Through the above analysis, this paper predicts that the APA behavior of listed enterprises, via the transmission of the information mechanism, can effectively reduce the information asymmetry of the capital market and thus suppress SPCR.

This paper empirically tests the influence of listed enterprise's APA on SPCR, with state-owned listed enterprises (SOLEs) trading A-shares on the main board of Shanghai
Stock Exchange and Shenzhen Stock Exchange. SOLEs were selected as the objects, because they are obliged to promote local economic and social development, in addition to undertaking corporate economic responsibility. These enterprises invest more manpower, materials, and money in APA than private enterprises and take the lead in this round of poverty alleviation campaign. Compared with the literature, the main contributions of this research are as follows:

(1) This paper expands the scope of SPCR research. In recent years, more and more scholars shifted their attention to SPCR of listed enterprises in China. But few explored SPCR from the angle of APA. This research gap is filled up by this research. APA differs significantly from CSR. Albeit an aspect of CSR, APA has different connotations and denotations from CSR, as manifested by its behavior and significance. As a result, there is an essential difference between our research results and the conclusions of previous CSR-based research of SPCR.

(2) This paper enriches the research into the economic consequences of APA. The existing studies on APA mostly discuss the influence of APA on corporate behavior, failing to tackle its influence on corporate performance in the capital market. In this paper, the influence of APA on SPCR of Chinese listed enterprises is tested, shedding light on the theories and practices of APA participation of Chinese listed enterprises and APA by the capital market.

(3) From the angle of information mechanism, this paper analyzes how APA suppresses SPCR and effectively verifies the action mechanism of APA on the capital market performance of Chinese listed enterprises, providing important insights into the external governance of listed enterprises in emerging markets.

\section{Theoretical Analysis and Hypothesis}

State-owned enterprises (SOEs) are both market players and executors of national will. They have become the main force of the APA campaign, thanks to their superiority in terms of talents, funds, projects, technologies, information, and management. This testifies that SOEs are giving dual attention to economic benefits and social responsibility. According to the official data of State-Owned Assets Supervision and Administration Commission of the State Council, as of the end of August 2020, central SOEs alone invested and introduced 4.228 billion yuan of free assistance funds to 246 designated poverty alleviation counties, trained 190,600 grassroots cadres and technicians, purchased and helped sell 3.921 billion yuan of agricultural products of poverty-stricken areas, aided the construction of 231 schools and 324 hospitals and health centers, provided financial aids to 130,600 poor students, and contributed 801 million yuan to compulsory education poverty alleviation, 284 million to medical poverty alleviation, 82.39 million to housing safety, and 116 million to drinking water safety. Central SOEs like PetroChina, China Huadian, and China State Construction 
stand out for their excellent performance in APA. The efforts of central SOEs not only promote the implementation of APA, but also highlight their sense of responsibility for local economic and social development.

Meanwhile, the poverty alleviation policies of the capital market provide an ideal platform for SOLEs to participate in APA. The cooperation between SOEs and capital market in poverty alleviation enables SOLEs to explore new poverty alleviation models, using the resources of the capital market, and to build a long-lasting mechanism of APA. After the absolute poverty is eradicated, the cooperation mechanism can ensure the poverty alleviation effect in the relative poverty period and give full play to the poverty alleviation functions of SOEs and the capital market. Under this mechanism, the capital market can effectively allocate, attract, and guide funds and resources, and the interests of market investors can be fully protected.

The effectiveness of SOE participation in APA is directly reflected in poverty elimination. In addition, as the CSRC standardizes the contents and means of APA information disclose by SOEs, the quantity, quality, and effectiveness of information disclosure by SOLEs will be improved substantially. Then, the information asymmetry between market investors and listed enterprises engaging in APA will be weakened, which in turn reduces SPCR of such enterprises.

Firstly, the regulatory standardization of APA information disclosure by listed enterprises effectively increases the quantity of information disclosed by listed enterprises engaging in APA. Market investors could fully master the APA information of listed enterprises, as well as many other information. As required by CSRC, Shanghai Stock Exchange, and Shenzhen Stock Exchange, listed enterprises can disclose the planning, annual summary, effects, and subsequent schemes of poverty alleviation by means of annual report, CSR report, and temporary report. In this way, market investors enjoy multiple channels and pathways to access the information of listed enterprises. They could learn the poverty alleviation information of listed enterprises more completely and derive more internal information of such enterprises from poverty alleviation information, especially the nonfinancial information unavailable in annual or quarterly report. Under the requirements of regulatory policies and the increase of disclosed information, the management of a listed enterprise engaging in APA have little profit motive to conceal unfavorable information or release information selectively. Even if they choose to conceal unfavorable information, only a few such information will be disclosed. In this case, insiders will be less likely to commit earnings manipulation or other bad behaviors, by virtue of their information superiority [14]. Furthermore, market investors can evaluate the operation condition and financial state of listed enterprises based on the APA information comprehensively [15] and make more reasonable judgment and decisions. Then, the values of listed enterprises will be reflected more accurately by stock prices, squeezing out the bubbles in the prices.

Secondly, as the listed enterprises engaging in APA disclose more information, the quality of APA information being disclosed will be improved, making the accounting of such enterprises more robust and market investors more secure. On APA information disclosure, the regulatory authorities not only demand listed enterprises to disclose more information, but also require them to build a good APA information disclosure system, following a series of regulations and constraints. Under the system, the listed enterprises engaging in APA must release more complete and accurate information timelier to the public, the capital market, and market investors. A good information disclosure system greatly enhances the accounting robustness of listed enterprises, ensures the contract efficiency between shareholders and the management, and thereby reduces the opportunistic behavior of the management. As a result, the interests of shareholders can be protected well under the system [16]. Besides fulfilling the economic responsibility of realizing corporate value and satisfying the interests of shareholders, SOLEs need to undertake social and political responsibilities of promoting national and local economy and meeting people's interests. Hence, it is highly necessary for SOLEs to improve accounting robustness by setting up APA information disclosure system. Under the constraints of regulatory authorities, listed enterprises can realize more robust accounting through timely disclose of complete and accurate APA information. Consequently, APA information will not simply be regarded as good information. The capital market will receive a more balanced influx of the good information and bad information of listed enterprises, which prevents the information bias against listed enterprises. Thus, market investors can judge APA information more clearly. In the meantime, the management will be less likely to disclose information selectively, so that market investors could organically combine the hard financial information in the annual report with the soft APA information [17] and avoid being misled by the management. This obviously suppresses the bad information concealment and SPCR [18].

Thirdly, the APA behavior and APA information disclosure shape a good image of listed enterprises in the public and the capital market, creating a good reputation effect similar to the reputation effect of CSR. The APA behavior of listed enterprises sends a signal of unselfishness to the public and the capital market and acts like a social capital to form a good corporate image, building up a better relationship with stakeholders [19]. By disclosing APA information, SOLEs obtains a good reputation effect, allowing the public and the capital market to understand their APA conditions. The disclosure means SOLEs are willing to shoulder the social responsibility of national and local economic development and unlikely to face the moral risk of opportunism. Hence, it is easy for the listed enterprises engaging in APA to win the favor and trust of market investors and therefore they are capable of resisting external operation risks and external risks of the capital market [20]. Through APA, listed enterprises can accumulate social reputation capital, which serves as a risk barrier [21]. The social reputation capital can effectively alleviate the impact of external adverse events and threats and prevent market investors from blinding attributing bad information to the subjective will of listed enterprises or their management. As a result, market investors will be less likely to vote by foot, and the SPCR will be mitigated.

To sum up, the following hypothesis was put forward: $\mathrm{H}$ : APA behavior helps to reduce the SPCR of SOLEs. 


\section{Research Design}

\subsection{Variable Design and Definition}

3.1.1. SPCR. Referring to Hutton et al. [22], Xu et al. [23], and Susnjara et al. [24], this paper measures SPCR with negative coefficient of skewness (Ncskew) and down-to-up volatility (Duvol) of each sample enterprise.

The first step is to calculate the weekly specific return rate of the sample enterprise after market adjustment, i.e., build the following model:

$$
\begin{aligned}
R_{i, t}= & \alpha_{0}+\alpha_{1} R_{m, t-2}+\alpha_{2} R_{m, t-1}+\alpha_{3} R_{m, t} \\
& +\alpha_{4} R_{m, t+1}+\alpha_{5} R_{m, t+2}+\varepsilon_{i, t},
\end{aligned}
$$

where $R_{i, t}$ is the return rate of the reinvestment of the sample enterprise considering cash dividend; $R_{m, t}$ is the mean return weighted by circulation market value of the main board market; $t$ is the number of weeks. Meanwhile, referring to Xu et al. [23], the market returns in the previous and subsequent weeks were added to the above model. Since the residual terms obtained by formula (1) obey skewed distribution, formula (1) can be corrected as

$$
W_{i, t}=\ln \left(1+\varepsilon_{i, t}\right) \text {. }
$$

On this basis, Ncskew and Duvol can be calculated by

$$
\begin{gathered}
\text { Ncskew }_{i, t}=-\frac{\left[n(n-1)^{3 / 2} \sum W_{i, t}^{3}\right]}{\left[(n-1)(n-2)\left(\sum W_{i, t}^{2}\right)^{3 / 2}\right]}, \\
\text { Duvol }_{i, t}=\log \left\{\frac{\left[\left(n_{u}-1\right) \sum_{\text {down }} W_{i, t}^{2}\right]}{\left[\left(n_{d}-1\right) \sum_{\mathrm{up}} W_{i, t}^{2}\right]}\right\} .
\end{gathered}
$$

The greater the values of Ncskew and Duvol, the higher the SPCR of the sample enterprise.

\subsection{2. $A P A$}

(1) APA behavior $\left(\mathrm{APA}_{1}\right)$. Since the regulatory authorities demand listed enterprises to disclose their APA information, this paper measures the presence/ absence of APA behavior by a dummy variable: whether the sample enterprise discloses APA information. If the sample enterprise commits APA behavior, $\mathrm{APA}_{1}=1$; otherwise, $\mathrm{APA}_{1}=0$.

(2) APA degree $\left(\mathrm{APA}_{2}\right)$. The APA degree was measured by the natural logarithm of the APA investment disclosed by the sample enterprise. If the sample enterprise does not participate in APA, then $\mathrm{APA}_{2}=0$.

3.1.3. Information Disclosure (IND). Referring to Hutton et al. [22], this paper measures the degree of information disclosure of the sample enterprise with information transparency. Based on the modified Jones model designed by Dechow et al. [25], information transparency was calculated by solving the sum of the absolute values of the discretionary accruals of the sample enterprise in the previous three years and multiplying the sum with -1 . The greater the obtained value, the better the degree of information disclosure by the sample enterprise.

3.1.4. Control Variables. Drawing on the literature on SPCR, this paper adds the following control variables: average weekly specific yield rate (Awcy), i.e., the mean of $W$ in formula (2); standard deviation of weekly specific yield rate (Swcy), i.e., the standard deviation of $W$ in formula (2); asset size (Size), i.e., the natural logarithm of the total assets of the sample enterprise; debt-to-asset ratio (Debt), i.e., the debtto-asset ratio of the sample enterprise; return on assets (Roa), i.e., the return on assets of the sample enterprise; equity concentration (H10), i.e., the quadratic sum of the shareholding ratios of the top 10 shareholders of the sample enterprise; audit supervision (Big4), a dummy variable of whether the accounting firm hired by the sample enterprise is among the big four accounting firms; central SOE (CSE), a dummy variable of whether the sample enterprise is a central SOE or a local SOE; public welfare SOE (PSE), a dummy variable of whether the sample enterprise is a public welfare SOE or a commercial SOE.

\subsection{Design of Empirical Models}

3.2.1. Design of the Benchmark Regression Model. To test the research hypothesis, the following empirical model was designed:

$$
\begin{aligned}
\mathrm{SPCR}_{i, t+1}= & \alpha_{1} \mathrm{APA}_{i, t}+\alpha_{i} \text { Control_Variable }_{i, t} \\
& + \text { Year }+ \text { Industry }+C+\varepsilon_{i, t},
\end{aligned}
$$

where Control_Variable is a set of control variables and $C$ is a constant. Considering the lag of SPCR influence, explanatory variables and control variables with one phase lag were added to the empirical model. In addition, the year (Year) and industry (Industry) factors of the sample enterprise were controlled.

3.2.2. Design of the Mediating Effect Model. The previous analysis indicates that information disclosure mediates the relationship between APA and SPCR. Based on formula (4), a model was designed to test the mediating effect of information disclosure:

$$
\begin{aligned}
\mathrm{IND}_{i, t}= & \beta_{1} \mathrm{APA}_{i, t}+\beta_{i} \text { Control_Variable }_{i, t}+\text { Year } \\
& + \text { Industry }+C+\varepsilon_{i, t}, \\
\mathrm{SPCR}_{i, t+1}= & \gamma_{1} \mathrm{APA}_{i, t}+\gamma_{2} \mathrm{IND}_{i, t}+\gamma_{i} \text { Control_Variable }_{i, t} \\
& + \text { Year }+ \text { Industry }+C+\varepsilon_{i, t} .
\end{aligned}
$$

If both $\beta_{1}$ and $\gamma_{2}$ are significant, then there exists a mediating effect. In this case, the mediating effect is partial when $\gamma_{1}$ is significant, and full when $\gamma_{1}$ is insignificant. If at least one of $\beta_{1}$ and $\gamma_{2}$ is insignificant, it is necessary to carry out a Sobel test. 
3.2.3. Design of the Endogeneity Model. The correlation between APA and SPCR could come from unobserved variables, calling for endogeneity test. Referring to Deng Bofu et al. [26], the proportion (SAPA) of APA participation among other SOLEs in the same industry and region as the sample enterprise was taken as an instrumental variable, and the endogeneity was tested by two-stage least squares method. The test model of the first stage can be expressed as

$$
\begin{aligned}
\mathrm{APA}_{i, t}= & \alpha_{1} \mathrm{SAPA}_{i, t}+\alpha_{i} \text { Control_Variable } \\
& + \text { Year }+ \text { Industry }+C+\varepsilon_{i, t} .
\end{aligned}
$$

The instrumental variable was selected for two reasons: Firstly, whether other SOLEs participate in APA affects the APA decision of the listed enterprise, which satisfies the correlation requirement of instrumental variables; secondly, the decision of other SOLEs does not affect the SPCR of the listed enterprise, which meets the endogeneity requirement of instrumental variables.

3.3. Data Description. The original samples were the SOLEs trading A-shares on the main board of Shanghai Stock Exchange and Shenzhen Stock Exchange in 2016-2018. These SOLEs were selected in the light of the outstanding performance of SOEs in this round of poverty alleviation campaign and the regulatory requirement that all listed enterprises must disclose APA information more systematically and completely as of 2016. The original samples were preprocessed by the following principles: (1) removing the sample enterprises in finance, insurance, and security industries; (2) eliminating the sample enterprises receiving special treatment; (3) deleting the sample enterprises listed simultaneously in B-share or $\mathrm{H}$-share markets; (4) removing the sample enterprises that trade less than 30 weeks per year in the stock market; (5) eliminating the sample enterprises that realize initial public offering (IPO) in the current year. After the preprocessing, a total of 2,315 year-samples of 938 SOLEs in 2016-2019 were obtained. The data source is China Stock Market and Accounting Research (CSMAR) Database.

\section{Empirical Results and Analysis}

4.1. Descriptive Statistics and Analysis. Table 1 lists the descriptive statistics of the main variables. The means of Ncskew and Duvol were -0.305 and -0.194 , respectively. The results are similar to the statistics of domestic researchers like Dong et al. [27] and Liang et al. [28] but obviously smaller than the statistics obtained by Kim et al. [6] and Chowdhury et al. [29] from foreign stock market data. Hence, Chinese stock market has a smaller SPCR than foreign stock markets.

The mean of variable $\mathrm{APA}_{1}$ amounted to 0.435 , suggesting that around $43.5 \%$ of sample SOLEs participate in APA. The mean of variable $\mathrm{APA}_{2}$ stood at 5.356, indicating that SOLEs on average invest 2.1188 million yuan to APA. In reality, the SOLEs actually engaging in APA invest an average of 2.199 billion yuan to poverty alleviation.

Table 2 presents the descriptive statistics on different groups of sample enterprises. Firstly, the SOEs were tested by whether they participate in APA. The grouped results show that the SOLEs engaging in APA had lower mean and median of Ncskew and Duvol than those not engaging in APA, and the values all passed the significance test at normal levels. Hence, the SOLEs engaging in APA face a lower SPCR than those not engaging in APA, which preliminarily verifies the research hypothesis.

Next, the SOEs were tested by whether they belong to central SOE or local SOE. Compared with local SOEs, central SOEs had a relatively low SPCR and tended to participate in and invest heavily in APA. This is because central SOEs boast a relatively strong economic power and need to undertake more national responsibilities.

Further, the SOEs were tested by whether they are public welfare SOE or commercial SOE. Compared with commercial SOEs, public welfare SOEs had a relatively low SPCR and tended to participate in and invest heavily in APA. The result has something to do with the public welfare attribute of public welfare SOEs.

In addition, the sample SOLEs were grouped by the degree of APA input. The SOLEs not engaging in APA were allocated to one group, and the other SOLEs engaging in APA were divided into 9 groups by APA input. Figure 1 shows the mean SPCR of each group. It can be observed that, with the increase of APA input, the mean SPCR exhibited an overall decline. This means, as SOLEs invest more to APA, the capital market will acknowledge the APA behavior of SOLEs, and SPCR will be mitigated. The result is in line with the research hypothesis.

4.2. Correlation Test Results and Analysis. Table 3 gives the results of the correlation test on the variables. The correlation coefficient between Ncskew and Duvol reached 0.871, a sign of the high correlation between the two metrics of SPCR degree. The correlation coefficient was negative between APA1 and Ncskew and Duvol and between APA2 and Ncskew and Duvol. Therefore, the APA of sample enterprises is negatively correlated with SPCR, which is consistent with the research hypothesis. In addition, the correlation coefficients were not high between explanatory variables and control variables or between control variables. As a result, there is no collinearity problem between the variables.

4.3. Multiple Regression Results and Analysis. Table 4 lists the multiple regression results. The regression results (1)-(4) show a significant negative correlation between explanatory variable $\mathrm{APA}_{1}$ and explained variables Ncskew and Duvol. This means the SOLEs engaging in APA have a lower SPCR than those not engaging in APA. The regression results (5)-(6) show a significant negative correlation between explanatory variable $\mathrm{APA}_{2}$ and explained variables Ncskew and Duvol. Thus, the SPCR decreases with the growing APA input by SOLEs. The regression results confirm the research hypothesis: SPCR can be effectively suppressed by SOLEs' APA behavior, which produces a good effect, and wins the recognition of the capital market and market investors.

A robustness test was conducted to verify if the empirical results are robust. Firstly, propensity score matching was 
Table 1: Descriptive statistics.

\begin{tabular}{|c|c|c|c|c|c|c|c|}
\hline Variable & Mean & Medium & Standard deviation & $5 \%$ & $25 \%$ & $75 \%$ & $95 \%$ \\
\hline Ncskew & -0.305 & -0.275 & 0.685 & -1.454 & -0.697 & 0.116 & 0.743 \\
\hline Duvol & -0.194 & -0.203 & 0.463 & -0.934 & -0.504 & 0.110 & 0.559 \\
\hline $\mathrm{APA}_{1}$ & 0.435 & 0.000 & 0.496 & 0.000 & 0.000 & 1.000 & 1.000 \\
\hline $\mathrm{APA}_{2}$ & 5.356 & 0.000 & 6.750 & 0.000 & 0.000 & 12.847 & 15.607 \\
\hline Awcy & -0.003 & -0.004 & 0.006 & -0.011 & -0.007 & 0.000 & 0.008 \\
\hline Swcy & 0.054 & 0.052 & 0.017 & 0.029 & 0.042 & 0.064 & 0.084 \\
\hline Size & 22.876 & 22.813 & 1.297 & 20.870 & 21.988 & 23.685 & 25.044 \\
\hline Debt & 0.491 & 0.497 & 0.203 & 0.157 & 0.333 & 0.646 & 0.823 \\
\hline Roa & 0.048 & 0.045 & 0.061 & -0.021 & 0.026 & 0.070 & 0.136 \\
\hline$H 10$ & 0.180 & 0.152 & 0.128 & 0.028 & 0.084 & 0.253 & 0.418 \\
\hline Big4 & 0.054 & 0.000 & 0.225 & 0.000 & 0.000 & 0.000 & 1.000 \\
\hline CSE & 0.199 & 0.000 & 0.399 & 0.000 & 0.000 & 0.000 & 1.000 \\
\hline PSE & 0.373 & 0.000 & 0.484 & 0.000 & 0.000 & 1.000 & 1.000 \\
\hline IND & 0.064 & 0.079 & 0.176 & -0.240 & -0.022 & 0.158 & 0.330 \\
\hline SAPA & 0.436 & 0.400 & 0.288 & 0.000 & 0.220 & 0.625 & 1.000 \\
\hline
\end{tabular}

TABLE 2: Grouped descriptive statistics.

\begin{tabular}{|c|c|c|c|c|c|c|c|c|}
\hline \multirow{2}{*}{ Variable } & \multicolumn{3}{|c|}{$\mathrm{APA}_{1}=1$} & \multicolumn{3}{|c|}{$\mathrm{APA}_{1}=0$} & \multirow{2}{*}{$T$-statistic } & \multirow{2}{*}{$Z$-score } \\
\hline & Sample size & Mean & Medium & Sample size & Mean & Medium & & \\
\hline Ncskew & 1008 & -0.367 & -0.307 & 1307 & -0.257 & -0.245 & $-3.821^{* * *}$ & $2.500^{* *}$ \\
\hline Duvol & 1008 & $\begin{array}{c}-0.234 \\
\mathrm{CSE}=1\end{array}$ & -0.230 & 1307 & $\begin{array}{c}-0.164 \\
\mathrm{CSE}=0\end{array}$ & -0.180 & $-3.622^{* * *}$ & $2.944^{* * *}$ \\
\hline Ncskew & 460 & -0.325 & -0.313 & 1855 & -0.300 & -0.266 & $-3.027^{* * *}$ & $3.149^{* * *}$ \\
\hline Duvol & 460 & -0.224 & -0.233 & 1855 & -0.187 & -0.188 & $-4.138^{* * *}$ & $4.340^{* * *}$ \\
\hline $\mathrm{APA}_{1}$ & 460 & 0.463 & 0.000 & 1855 & 0.429 & 0.000 & $4.359^{* * *}$ & $3.653^{* * *}$ \\
\hline $\mathrm{APA}_{2}$ & 460 & $\begin{array}{r}5.808 \\
\text { PSE }=1\end{array}$ & 0.000 & 1855 & $\begin{array}{r}5.244 \\
\mathrm{PSE}=0\end{array}$ & 0.000 & $4.078^{* * *}$ & $3.519^{* * *}$ \\
\hline Ncskew & 863 & -0.334 & -0.287 & 1452 & -0.287 & -0.269 & $-4.537^{* * *}$ & $4.379^{* * *}$ \\
\hline Duvol & 863 & -0.220 & -0.224 & 1452 & -0.179 & -0.182 & $-4.782^{* * *}$ & $4.762^{* * *}$ \\
\hline $\mathrm{APA}_{1}$ & 863 & 0.565 & 1.000 & 1452 & 0.358 & 0.000 & $9.930^{* * *}$ & $8.353^{* * *}$ \\
\hline $\mathrm{APA}_{2}$ & 863 & 7.171 & 10.463 & 1452 & 4.277 & 0.000 & $10.196^{* * *}$ & $8.674^{* * *}$ \\
\hline
\end{tabular}

Note. The symbols $* * *, * *$, and $*$ are the significance levels of $1 \%, 5 \%$, and $10 \%$, respectively.

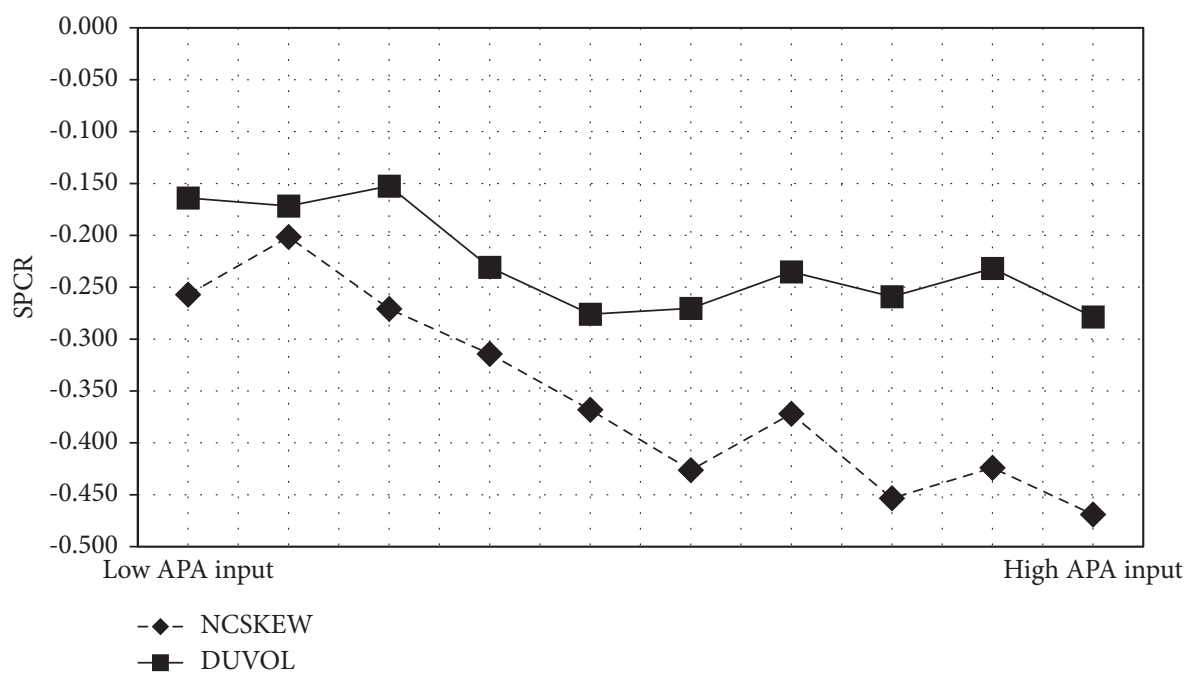

FIgURE 1: Distribution of APA and SPCR. 


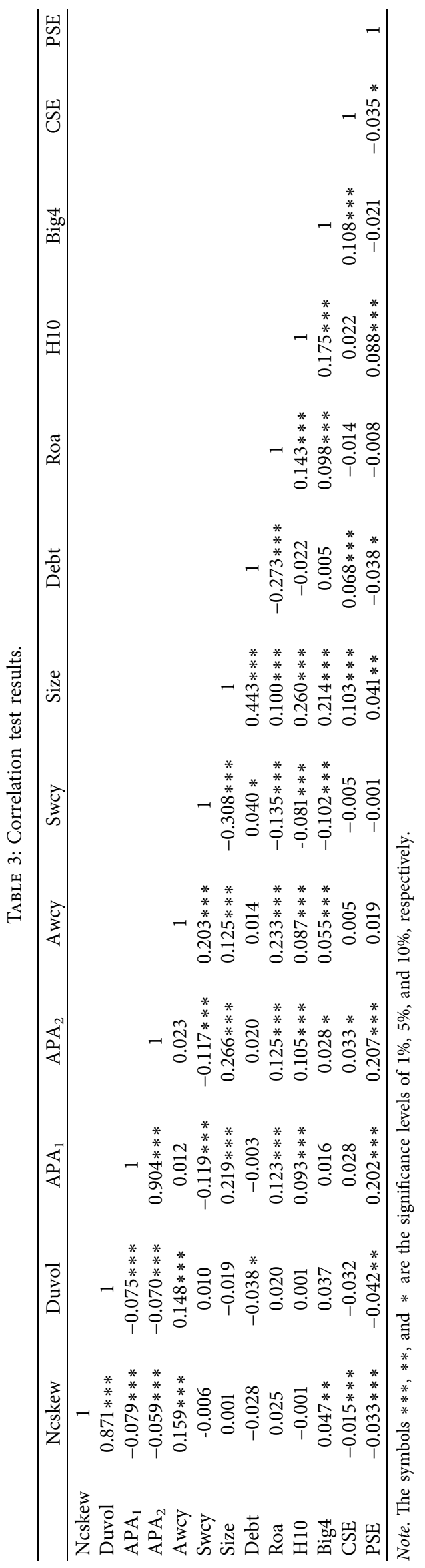


TABLE 4: Multiple regression results.

\begin{tabular}{|c|c|c|c|c|c|c|c|c|}
\hline & (1) Ncskew & (2) Duvol & (3) Ncskew & (4) Duvol & (5) Ncskew & (6) Duvol & (7) Ncskew & (8) Duvol \\
\hline $\mathrm{APA}_{1}$ & $\begin{array}{c}-0.109 * * * \\
(0.029)\end{array}$ & $\begin{array}{c}-0.070 * * * \\
(0.019)\end{array}$ & $\begin{array}{c}-0.108 * * * \\
(0.030)\end{array}$ & $\begin{array}{c}-0.062 * * * \\
(0.020)\end{array}$ & & & & \\
\hline $\mathrm{APA}_{2}$ & & & & & $\begin{array}{c}-0.006 * * * \\
(0.002)\end{array}$ & $\begin{array}{c}-0.005 * * * \\
(0.001)\end{array}$ & $\begin{array}{c}-0.006 * * * \\
(0.002)\end{array}$ & $\begin{array}{c}-0.004 * * * \\
(0.002)\end{array}$ \\
\hline Awcy & & & $20.523 * * *$ & $12.863 * * *$ & & & $20.606 * * *$ & $12.876 * * *$ \\
\hline Swcy & & & $-2.063 * *$ & $-0.971 *$ & & & $-1.999 * *$ & $-0.937 *$ \\
\hline Size & & & -0.003 & -0.006 & & & -0.004 & -0.006 \\
\hline Debt & & & $0.111 *$ & $0.088 *$ & & & $0.106 *$ & $0.087 *$ \\
\hline Roa & & & -0.273 & -0.208 & & & -0.295 & -0.211 \\
\hline$H 10$ & & & -0.071 & -0.018 & & & -0.072 & -0.018 \\
\hline Big4 & & & $-0.123 *$ & $0.074 *$ & & & $0.126 *$ & $0.075 *$ \\
\hline CSE & & & $-0.027 * * *$ & $-0.037 * * *$ & & & $-0.028 * * *$ & $-0.037 * * *$ \\
\hline PSE & & & $-0.029 * * *$ & $-0.032 * * *$ & & & $-0.034 * * *$ & $-0.032 * * *$ \\
\hline Year & Controlled & Controlled & Controlled & Controlled & Controlled & Controlled & Controlled & Controlled \\
\hline Industry & Controlled & Controlled & Controlled & Controlled & Controlled & Controlled & Controlled & Controlled \\
\hline & $-0.257 * * *$ & $-0.164 * * *$ & $0.073 * * *$ & $0.142 * * *$ & $-0.273 * * *$ & $-0.169 * * *$ & $0.079 * * *$ & $0.118 * * *$ \\
\hline $\operatorname{Adj} R^{2}$ & 0.006 & 0.005 & 0.034 & 0.030 & 0.003 & 0.005 & 0.031 & 0.029 \\
\hline
\end{tabular}

Note. The numbers in the parentheses are the standard error of regression coefficients; $* * *, * *$, and $*$ are the significance levels of $1 \%, 5 \%$, and $10 \%$, respectively.

adopted to eliminate the finance and governance heterogeneity between SOLEs engaging in APA and those not engaging in APA: the propensity scores of APA engagement were computed for the sample enterprises; each enterprise was matched with another enterprise based on the scores; the effective samples thus obtained were empirically tested. Next, the SOLEs located in municipalities directly under the central government, e.g., Beijing, were removed for empirical test, because this special type of administrative regions affects SOLE behaviors. After that, the SPCR metrics (dummy variables) other than Ncskew and Duvol were introduced for empirical test. There was no essential difference between the results of the robustness test and those of the previous empirical test, indicating that the regression results are robust.

4.4. Mediating Effect Test Results and Analysis. Table 5 displays the results of mediating effect test. Back in Table 4, the relationships between explanatory variables $\mathrm{APA}_{1}$ and $\mathrm{APA}_{2}$ and explained variables Ncskew and Duvol were significantly negative. In Table 4, regression results (1) and (2) reveal a significant positive relationship between variables $\mathrm{APA}_{1}$ and $\mathrm{APA}_{2}$ and the explained variable IND. Hence, information transparency increases with the APA engagement and APA input of SOLEs. This means SOLEs' APA behavior effectively improves the degree of information disclosure.

Regression results (3)-(6) show a significant negative relationship between the explanatory variable IND and explained variables Ncskew and Duvol, indicating that a high degree of information disclosure leads to a low SPCR of SOLEs. Therefore, a good information disclosure system can obviously suppress SPCR; i.e., the system effectively mediates the relationship between APA and SPCR. It can also be seen from regression results (3)-(6) that the negative correlations between explanatory variables $\mathrm{APA}_{1}$ and $\mathrm{APA}_{2}$ and explained variables Ncskew and Duvol all passed through the significance test at normal levels, suggesting that the information disclosure system has a partial mediating effect.
4.5. Endogeneity Test Results and Analysis. Table 6 provides the endogeneity test results. According to the results of the first stage, the explanatory variable SAPA had a significant positive correlation with explained variables $\mathrm{APA}_{1}$ and $\mathrm{APA}_{2}$. Hence, the sample enterprise is more likely to engage in and invest more in APA if a high proportion of enterprises in the same industry and region participate in APA.

According to the results of the second stage, significant negative correlations were observed between explanatory variables APA1 and APA2 and explained variables Ncskew and Duvol: APA behavior still suppresses SOLEs' SPCR, after considering endogenous factors.

In the regression results (3)-(6), the J-statistic of Sargan's test demonstrates the reasonability of the selected instrumental variable.

\subsection{Grouped Heterogeneity Test Results and Analysis}

4.6.1. Difference Test between Central SOEs and Local SOEs. There are certain differences between central SOEs and local SOEs in asset size, resource acquisition, and responsibility fulfilment. Therefore, the samples were divided into central SOEs and local SOEs for testing. The test results in Table 7 show that, for both central SOEs and local SOEs, significant negative correlations were observed between explanatory variables $\mathrm{APA}_{1}$ and $\mathrm{APA}_{2}$ and explained variables Ncskew and Duvol. These correlations all demonstrate the suppressing effect of APA on SPCR, indicating that the role of APA in the capital market exists in both central and local SOEs. Furthermore, central SOEs had higher absolute values of $\mathrm{APA}_{1}$ and $\mathrm{APA}_{2}$ than local SOEs; that is, APA behavior suppresses SPCR more significantly in central SOEs than local SOEs. This is because central SOEs boast a relatively strong economic power and need to undertake more national responsibilities. 
TABLE 5: Mediating effect test results.

\begin{tabular}{lcccccc}
\hline & (1) IND & (2) IND & (3) Ncskew & (4) Duvol & (5) Ncskew & $(6)$ Duvol \\
\hline APA $_{1}$ & $0.084 * * *(0.009)$ & & $-0.300 * * *(0.031)$ & $-0.172 * * *(0.022)$ & \\
$\mathrm{APA}_{2}$ & & $0.013 * * *(0.001)$ & & $-0.018 * * *(0.002)$ & $-0.012 * * *(0.002)$ \\
$\mathrm{IND}$ & & & $-0.101 * * *(0.009)$ & $-0.046 * * *(0.006)$ & $-0.116 * * *(0.009)$ & $-0.057 * * *(0.006)$ \\
Control_Variable & Controlled & Controlled & Controlled & Controlled & Controlled & Controlled \\
Year & Controlled & Controlled & Controlled & Controlled & Controlled & Controlled \\
Industry & Controlled & Controlled & Controlled & Controlled & Controlled & Controlled \\
$C$ & $0.799 * *$ & $0.826 * * *$ & $-0.054 * * *$ & $0.175 * * *$ & $-0.128 * * *$ & $0.089 * * *$ \\
Adj $R^{2}$ & 0.105 & 0.107 & 0.102 & 0.083 & 0.082 & 0.077 \\
\hline
\end{tabular}

Note. The numbers in the parentheses are the standard error of regression coefficients; $* * *, * *$, and $*$ are the significance levels of $1 \%$, $5 \%$, and $10 \%$, respectively.

TABLE 6: Endogeneity test results.

\begin{tabular}{|c|c|c|c|c|c|c|}
\hline & \multicolumn{3}{|c|}{ Stage 1} & \multicolumn{3}{|c|}{ Stage 2} \\
\hline & (1) $\mathrm{APA}_{1}$ & (2) $\mathrm{APA}_{2}$ & (3) Ncskew & (4) Duvol & (5) Ncskew & (6) Duvol \\
\hline SAPA & $\begin{array}{c}0.906 * * * \\
(0.034)\end{array}$ & $\begin{array}{c}11.067 * * * \\
(0.475)\end{array}$ & & & & \\
\hline $\mathrm{APA}_{1}$ & & & $\begin{array}{c}-0.289 * * * \\
(0.026)\end{array}$ & $\begin{array}{c}-0.168 * * * \\
(0.019)\end{array}$ & & \\
\hline $\mathrm{APA}_{2}$ & & & & & $\begin{array}{c}-0.017 * * * \\
(0.002)\end{array}$ & $\begin{array}{c}-0.011 * * * \\
(0.001)\end{array}$ \\
\hline Control_Variable & Controlled & Controlled & Controlled & Controlled & Controlled & Controlled \\
\hline Year & Controlled & Controlled & Controlled & Controlled & Controlled & Controlled \\
\hline Industry & Controlled & Controlled & Controlled & Controlled & Controlled & Controlled \\
\hline C & $-1.568 * * *$ & $-30.008 * * *$ & $0.008 * * *$ & $0.172 * * *$ & $-0.049 * * *$ & $0.106 * * *$ \\
\hline $\operatorname{Adj} R^{2}$ & 0.345 & 0.318 & 0.094 & 0.072 & 0.074 & 0.064 \\
\hline J-statistic & - & - & 0.946 & 2.488 & 1.724 & 1.644 \\
\hline
\end{tabular}

Note. The numbers in the parentheses are the standard error of regression coefficients; $* * *, * *$, and $*$ are the significance levels of $1 \%$, $5 \%$, and $10 \%$, respectively.

TABLE 7: SOEs and local SOEs.

\begin{tabular}{|c|c|c|c|c|c|c|c|c|}
\hline & \multicolumn{4}{|c|}{ Test results on central SOEs } & \multicolumn{4}{|c|}{ Test results on local SOEs } \\
\hline & (1) Ncskew & (2) Duvol & (3) Ncskew & (4) Duvol & (5) Ncskew & (6) Duvol & (7) Ncskew & (8) Duvol \\
\hline $\mathrm{APA}_{1}$ & $\begin{array}{c}-0.165 * * * \\
(0.008)\end{array}$ & $\begin{array}{c}-0.102 * * * \\
(0.005)\end{array}$ & & & $-0.100 * * *(0.033)$ & $\begin{array}{c}-0.057 * * \\
(0.023)\end{array}$ & & \\
\hline $\mathrm{APA}_{2}$ & & & $\begin{array}{c}-0.013 * * * \\
(0.005)\end{array}$ & $\begin{array}{c}-0.008 * * * \\
(0.003)\end{array}$ & & & $\begin{array}{c}-0.005 * \\
(0.002)\end{array}$ & $\begin{array}{c}-0.004 * * \\
(0.002)\end{array}$ \\
\hline Control_Variable & Controlled & Controlled & Controlled & Controlled & Controlled & & Controlled & Controlled \\
\hline Year & Controlled & Controlled & Controlled & Controlled & Controlled & & Controlled & Controlled \\
\hline Industry & Controlled & Controlled & Controlled & Controlled & Controlled & Controlled & Controlled & Controlled \\
\hline C & $-1.663 * * *$ & $-1.175 * * *$ & $-1.868 * * *$ & $-1.299 * * *$ & $0.452 * * *$ & $0.431 * * *$ & $0.481 * * *$ & $0.417 * * *$ \\
\hline $\operatorname{Adj} R^{2}$ & 0.034 & 0.036 & 0.036 & 0.037 & 0.037 & 0.034 & 0.034 & 0.033 \\
\hline
\end{tabular}

Note. The numbers in the parentheses are the standard error of regression coefficients; $* * *, * *$, and $*$ are the significance levels of $1 \%, 5 \%$, and $10 \%$, respectively.

4.6.2. Difference Test between Public Welfare SOEs and Commercial SOEs. In September 2015, the central government of China divided SOEs into public welfare SOEs and commercial SOEs. The former SOEs need to focus on satisfying social needs, while the latter SOEs are more competitive. Therefore, this paper divides samples into public welfare SOEs and commercial SOEs before testing. The test results in Table 8 show that, for both public welfare SOEs and commercial SOEs, significant negative correlations were observed between explanatory variables $\mathrm{APA}_{1}$ and $\mathrm{APA}_{2}$ and explained variables Ncskew and Duvol. These correlations all demonstrate the suppressing effect of APA on SPCR. In addition, APA suppresses SPCR more significantly in public welfare SOEs than commercial SOEs. This is related to the special attribute of public welfare SOEs.

\section{Extended Tests under Different Scenarios and Results Analysis}

5.1. APA and SPCR under Institutional Environment. Institutional environment is an external environment of listed enterprises. If the institutional environment is 
TABLE 8: Sample test on public welfare SOEs and commercial SOEs.

\begin{tabular}{|c|c|c|c|c|c|c|c|c|}
\hline & \multicolumn{4}{|c|}{ Test results on public welfare SOEs } & \multicolumn{4}{|c|}{ Test results on commercial SOEs } \\
\hline & (1) Ncskew & (2) Duvol & (3) Ncskew & (4) Duvol & (5) Ncskew & (6) Duvol & (7) Ncskew & (8) Duvol \\
\hline $\mathrm{APA}_{1}$ & $\begin{array}{c}-0.120 * * * \\
(0.039)\end{array}$ & $\begin{array}{c}-0.076 * * * \\
(0.026)\end{array}$ & & & $\begin{array}{c}-0.088 * * * \\
(0.005)\end{array}$ & $\begin{array}{c}-0.041 * * * \\
(0.003)\end{array}$ & & \\
\hline $\mathrm{APA}_{2}$ & & & $\begin{array}{c}-0.042 * * * \\
(0.003)\end{array}$ & $\begin{array}{c}-0.030 * * * \\
(0.002)\end{array}$ & & & $\begin{array}{c}-0.007 * * \\
(0.003)\end{array}$ & $\begin{array}{c}-0.005 * * * \\
(0.002)\end{array}$ \\
\hline Control_Variable & Controlled & Controlled & Controlled & Controlled & Controlled & Controlled & Controlled & Controlled \\
\hline Year & Controlled & Controlle & Controlled & Controlled & Controlled & Controlled & Controlled & Controlled \\
\hline Industry & Controlled & Controlled & Controlled & Controlled & Controlled & Controlled & Controlled & Controlled \\
\hline & $0.768 * * *$ & $0.419 * * *$ & $0.765 * * *$ & $0.390 * * *$ & $-0.341 * * *$ & $-0.042 * * *$ & $-0.331 * * *$ & $-0.063 * * *$ \\
\hline $\operatorname{Adj} R^{2}$ & 0.040 & 0.022 & 0.038 & 0.022 & 0.027 & 0.029 & 0.024 & 0.028 \\
\hline
\end{tabular}

Note. The numbers in the parentheses are the standard error of regression coefficients; $* * *, * *$, and $*$ are the significance levels of $1 \%, 5 \%$, and $10 \%$, respectively.

desirable, the environment of the enterprise will be much less uncertain. Hence, institutional environment is an important determinant of corporate governance effect, exerting a major impact on the decision of economic players. A good institutional environment will weaken the information asymmetry between the enterprise and the outside and curb the agency problem within the listed enterprise, thereby suppressing SPCR [30]. This paper measures institutional environment with provincial marketization index (PMI) and adds the variable as a cross item to formula (4) for empirical test.

Table 9 lists the results under institutional environment. Regression results (1) and (2) show a significant negative correlation between PMI and explained variables Ncskew and Duvol, indicating that the better the institutional environment at the locality of SOLEs, the lower the SPCR. This finding verifies the governance effect of institutional environment.

Regression results (3) and (4) show that the coefficients of $\mathrm{APA}_{1}$ and PMI were significantly negative, so was the coefficient of the cross term. Similar results were obtained in (5) and (6). Therefore, institutional environment regulates the relationship between APA and SPCR. That is, the better the institutional environment at the locality of SOLEs, the greater the suppressing effect of APA on SPCR.

5.2. APA and SPCR under Poverty Alleviation Pressure. Due to the provincial difference in economic development level, SOLEs, especially SOLEs in the same province, face different levels of APA pressure. The pressure difference affects the recognition of APA effect by the capital market. Referring to Deng et al. [26], this paper measures poverty alleviation pressure (PAP) with the rural poor population as a proportion of the total population in the province in the current year and adds the variable as a cross item to formula (4) for empirical test.

Tables 9 and 10 list the results under poverty alleviation pressure. Regression results (1) and (2) show a significant positive correlation between PAP and explained variables Ncskew and Duvol, indicating that the greater the poverty alleviation pressure at the locality of SOLEs, the higher the external pressure on the enterprises; the high pressure will be reflected in the capital market, pushing up the implicit SPCR of the enterprises.

Regression results (3) and (4) show that the coefficients of $\mathrm{APA}_{1}$ and PAP were significantly negative, so was the coefficient of the cross term. Similar results were obtained in (5) and (6). Therefore, the suppressing effect of APA on SPCR increases with the poverty alleviation pressure at the locality of SOLEs. Despite pushing up the SPCR of SOLEs, a high poverty alleviation pressure boosts the capital market's recognition of SOLEs' APA behavior and thus enhances the suppression of APA on SPCR.

\subsection{APA and SPCR under Poverty Experience of Executives.} The early experience affects the character, temper, and personality of executives, which in turn influence their cognition, judgment, and decision. The decision of the listed enterprise will inevitably be affected [31]. As a pioneer in the research of poverty experience of executives, Malmendier et al. [32] pointed out that the executives who grew up during the Great Depression tend to make conservative decisions. $\mathrm{Xu}$ and $\mathrm{Li}$ [33] also stated that if they experienced poverty during the growth, executives will be very likely to contrast past misery with present happiness and more willing to make charitable donations. To sum up, executives who have poverty experience are very conservative and cautious in decision-making, which stabilize corporate performance in the capital market, and very clear about the connotations of APA. Referring to Xu and Li [33], this paper defines general managers born in 1947-1961 as executives with poverty experience, designs the variable of poverty experience of executives (EPE), and adds the variable as a cross item to formula (4) for empirical test.

Table 11 reports the test results under poverty experience of executives. Regression results (1) and (2) show a significant negative correlation between EPE and explained variables Ncskew and Duvol, suggesting that the general manager of an SOLE tends to make rational and cautious decisions, if he/she experienced poverty in youth; this helps to suppress the SPCR of his/her enterprise.

Regression results (3) and (4) show that the coefficients of $\mathrm{APA}_{1}$ and EPE were significantly negative, so was the coefficient of the cross term. Similar results were obtained in 
TABLE 9: Test results under institutional environment.

\begin{tabular}{|c|c|c|c|c|c|c|}
\hline & (1) Ncskew & (2) Duvol & (3) Ncskew & (4) Duvol & (5) Ncskew & (6) Duvol \\
\hline $\mathrm{APA}_{1}$ & & & $\begin{array}{c}-0.097 * * * \\
(0.012)\end{array}$ & $\begin{array}{c}-0.021 * * * \\
(0.008)\end{array}$ & & \\
\hline $\mathrm{APA}_{2}$ & & & & & $-0.051 * * *(0.009)$ & $\begin{array}{c}-0.009 * * * \\
\quad(0.001)\end{array}$ \\
\hline $\mathrm{APA}_{1} \times \mathrm{PMI}$ & & & $\begin{array}{c}-0.053 * * * \\
(0.014)\end{array}$ & $\begin{array}{c}-0.075 * * * \\
(0.010)\end{array}$ & & \\
\hline $\mathrm{APA}_{2} \times \mathrm{PMI}$ & & & & & $-0.014 * * *(0.001)$ & $\begin{array}{c}-0.042 * * * \\
\quad(0.007)\end{array}$ \\
\hline PMI & $\begin{array}{c}-0.015 * * \\
(0.007)\end{array}$ & $\begin{array}{c}-0.051 * * * \\
\quad(0.005)\end{array}$ & $\begin{array}{c}-0.011 * * * \\
\quad(0.001)\end{array}$ & $\begin{array}{c}-0.061 * * * \\
(0.007)\end{array}$ & $-0.012 * * *(0.001)$ & $\begin{array}{c}-0.053 * * * \\
\quad(0.007)\end{array}$ \\
\hline Control_Variable & Controlled & Controlled & Controlled & Controlled & Controlled & Controlled \\
\hline Year & Controlled & Controlled & Controlled & Controlled & Controlled & Controlled \\
\hline Industry & Controlled & Controlled & Controlled & Controlled & Controlled & Controlled \\
\hline C & $0.170 * * *$ & $0.216 * * *$ & $0.026 * * *$ & $0.099 * * *$ & $0.031 * * *$ & $0.085 * * *$ \\
\hline $\operatorname{Adj} R^{2}$ & 0.030 & 0.026 & 0.034 & 0.029 & 0.031 & 0.029 \\
\hline
\end{tabular}

Note. The numbers in the parentheses are the standard error of regression coefficients; $* * *, * *$, and $*$ are the significance levels of $1 \%, 5 \%$, and $10 \%$, respectively.

TABLE 10: Test results under poverty alleviation pressure.

\begin{tabular}{lcccccc}
\hline & $(1)$ Ncskew & (2) Duvol & (3) Ncskew & (4) Duvol & (5) Ncskew & $(6)$ Duvol \\
\hline $\mathrm{APA}_{1}$ & & & $-0.138 * * *(0.037)$ & $-0.090 * * *(0.025)$ & \\
$\mathrm{APA}_{2}$ & & & & $-0.008 * * *(0.002)$ & $-0.006 * * *(0.002)$ \\
$\mathrm{APA}_{1} \times \mathrm{PAP}$ & & & $-1.830 * * *(0.013)$ & $-1.385 * * *(0.091)$ & \\
$\mathrm{APA}_{2} \times \mathrm{PAP}$ & & & & $-0.113 * * *(0.010)$ & $-0.078 * * *(0.006)$ \\
$\mathrm{PAP}$ & $0.331 * * *(0.069)$ & $0.503 * * *(0.047)$ & $0.873 * * *(0.101)$ & $0.331 * * *(0.068)$ & $0.779 * * *(0.095)$ & $0.223 * * *(0.064)$ \\
Control_Variable & Controlled & Controlled & Controlled & Controlled & Controlled & Controlled \\
Year & Controlled & Controlled & Controlled & Controlled & Controlled & Controlled \\
Industry & Controlled & Controlled & Controlled & Controlled & Controlled & Controlled \\
C & $0.270 * * *$ & $0.210 * * *$ & $0.071 * * *$ & $0.088 * * *$ & $0.089 * * *$ & $0.063 * * *$ \\
Adj $R^{2}$ & 0.028 & 0.026 & 0.034 & 0.031 & 0.031 & 0.030 \\
\hline
\end{tabular}

Note. The numbers in the parentheses are the standard error of regression coefficients; $* * *, * *$, and $*$ are the significance levels of $1 \%, 5 \%$, and $10 \%$, respectively.

TABLE 11: Test results under poverty experience of executives.

\begin{tabular}{|c|c|c|c|c|c|c|}
\hline & (1) Ncskew & (2) Duvol & (3) Ncskew & (4) Duvol & (5) Ncskew & (6) Duvol \\
\hline $\mathrm{APA}_{1}$ & & & $\begin{array}{c}-0.095 * * * \\
(0.032)\end{array}$ & $-0.050 * *(0.022)$ & & \\
\hline $\mathrm{APA}_{2}$ & & & & & $-0.005 * *(0.002)$ & $\begin{array}{c}-0.003 * * * \\
(0.001)\end{array}$ \\
\hline $\mathrm{APA}_{1} \times \mathrm{EPE}$ & & & $\begin{array}{c}-0.105 * * * \\
(0.008)\end{array}$ & $-0.090 * *(0.026)$ & & \\
\hline $\mathrm{APA}_{2} \times \mathrm{EPE}$ & & & & & $\begin{array}{c}-0.078 * * * \\
(0.006)\end{array}$ & $\begin{array}{c}-0.063 * * * \\
(0.004)\end{array}$ \\
\hline $\mathrm{EPE}$ & $\begin{array}{c}-0.139 * * * \\
(0.012)\end{array}$ & $\begin{array}{c}-0.243 * * * \\
(0.028)\end{array}$ & $\begin{array}{c}-0.169 * * * \\
(0.015)\end{array}$ & $\begin{array}{c}-0.265 * * * \\
(0.038)\end{array}$ & $\begin{array}{c}-0.161 * * * \\
(0.024)\end{array}$ & $\begin{array}{c}-0.263 * * * \\
(0.036)\end{array}$ \\
\hline Control_Variable & Controlled & Controlled & Controlled & Controlled & Controlled & Controlled \\
\hline Year & Controlled & Controlled & Controlled & Controlled & Controlled & Controlled \\
\hline Industry & Controlled & Controlled & Controlled & Controlled & Controlled & Controlled \\
\hline$C$ & $0.244 * * *$ & $0.283 * * *$ & $0.046 * * *$ & $0.165 * * *$ & $0.049 * * *$ & $0.137 * * *$ \\
\hline
\end{tabular}

Note. The numbers in the parentheses are the standard error of regression coefficients; $* * *, * *$, and $*$ are the significance levels of $1 \%, 5 \%$, and $10 \%$, respectively.

(5) and (6). This means the poverty experience of executives regulates the relationship between APA and SPCR. That is, if the general management of an SOLE experienced poverty, APA will exert a greater suppression effect on SPCR. It can be seen that executives who have experienced poverty can better understand the significance of APA and would devote more energy and resources to APA. In this case, the APA effect will definitely be improved. 
TABLE 12: Test results under the model of party organization governance.

\begin{tabular}{|c|c|c|c|c|c|c|}
\hline & (1) Ncskew & (2) Duvol & (3) Ncskew & (4) Duvol & (5) Ncskew & (6) Duvol \\
\hline $\mathrm{APA}_{1}$ & & & $\begin{array}{c}-0.110 * * * \\
(0.031)\end{array}$ & $\begin{array}{c}-0.059 * * * \\
(0.021)\end{array}$ & & \\
\hline $\mathrm{APA}_{2}$ & & & & & $-0.006 *(0.002)$ & $\begin{array}{c}-0.004 * * * \\
(0.001)\end{array}$ \\
\hline $\mathrm{APA}_{1} \times \mathrm{POG}$ & & & $\begin{array}{c}-0.050 * * * \\
(0.016)\end{array}$ & $\begin{array}{c}-0.106 * * * \\
(0.011)\end{array}$ & & \\
\hline $\mathrm{APA}_{2} \times \mathrm{POG}$ & & & & & $\begin{array}{c}-0.016 * * * \\
(0.001)\end{array}$ & $\begin{array}{c}-0.008 * * * * \\
(0.001)\end{array}$ \\
\hline POG & $\begin{array}{c}-0.075 * * * \\
(0.008)\end{array}$ & $\begin{array}{c}-0.036 * * * \\
(0.006)\end{array}$ & $\begin{array}{c}-0.093 * * * \\
(0.012)\end{array}$ & $\begin{array}{c}-0.040 * * * \\
\quad(0.008)\end{array}$ & $\begin{array}{c}-0.064 * * * \\
(0.012)\end{array}$ & $\begin{array}{c}-0.046 * * * \\
(0.008)\end{array}$ \\
\hline Control_Variable & Controlled & Controlled & Controlled & Controlled & Controlled & Controlled \\
\hline Year & Controlled & Controlled & Controlled & Controlled & Controlled & Controlled \\
\hline Industry & Controlled & Controlled & Controlled & Controlled & Controlled & Controlled \\
\hline C & $0.223 * * *$ & $0.264 * * *$ & $0.049 * * *$ & $0.105 * * *$ & $0.052 * * *$ & $0.123 * * *$ \\
\hline $\operatorname{Adj} R^{2}$ & 0.027 & 0.024 & 0.031 & 0.028 & 0.029 & 0.028 \\
\hline
\end{tabular}

Note. The numbers in the parentheses are the standard error of regression coefficients; $* * *, * *$, and $*$ are the significance levels of $1 \%, 5 \%$, and $10 \%$, respectively.

5.4. APA and SPCR under the Model of Party Organization Governance. Party organization governance is a unique corporate governance model for Chinese SOEs. Under this model, the same group of people work in both the party organization and senior management, and the major issues of the enterprise are discussed in advance by the party committee. The model of party organization governance gives full play to governance and supervision and substantially improves corporate information disclosure system. Referring to Cheng et al. [34], this paper defines the behavior that the general manager of the sample enterprise works simultaneously as the secretary or deputy secretary of the party committee as the behavior of party organization governance, designs the variable for the model of party organization governance (POG), and adds the variable as a cross item to formula (4) for empirical test.

Table 12 presents the test results under the model of party organization governance and reports the test results under poverty experience of executives. Regression results (1) and (2) show a significant negative correlation between POG and explained variables Ncskew and Duvol, which implies that the SOLEs under the model of party organization governance have a relatively low SPCR. Hence, the model of party organization governance substantially lowers the implicit SPCR of the enterprises.

Regression results (3) and (4) show that the coefficients of $\mathrm{APA}_{1}$ and POG were significantly negative, so was the coefficient of the cross term. Similar results were obtained in (5) and (6). This means the model of party organization governance enhances the suppression of APA on SPCR. Thus, the presence of party organization governance effectively drives the APA behavior of the enterprises, ensures the long-term effectiveness of APA in various dimensions, regulates the APA behavior of SOEs (e.g., encouraging SOLEs engaging in APA to disclose information timelier and more accurately), and thus cuts down the SPCR of listed enterprises engaging in APA.

\section{Conclusions and Suggestions}

In recent years, more and more listed enterprises, especially SOLEs, actively engaged in APA. Their actions effectively optimize the allocation of social resources and build good corporate images by disclosing more APA information. As a result, listed enterprises engaging in APA would perform better in the stock market. From the angle of SPCR, this paper empirically tests the influence of APA on SPCR, focusing on SOLEs trading A-shares on the main board of Shanghai Stock Exchange and Shenzhen Stock Exchange in 2016-2018. It was learned that APA behavior can effectively suppress SOLE's SPCR; that is, SOLEs engaging in APA have a lower SPCR than those not engaging in APA, and SPCR decreases with the growing APA input of SOLEs. This conclusion holds after the control of robustness and endogenous factors. Information disclosure system mediates the effect of APA on SPCR. Besides, APA suppresses SPCR more significantly in central SOEs and public welfare SOEs. Further analysis indicates that good institutional environment, strong poverty alleviation pressure, poverty experience of executives, and model of party organization governance can effectively enhance the influence of APA on SPCR.

Based on the above empirical evidence, the following suggestions were presented:

Firstly, SOEs should take more initiative in APA engagement. SOEs have the economic strength to participate in APA, as well as the responsibility of driving national and regional economic development through APA. In particular, local SOEs are familiar with the current state and uniqueness of local economic development and more likely to recognize, assist with, and manage APA precisely. Therefore, SOEs should step up APA participation. After absolute poverty was eradicated in 2020, SOEs must build up the APA model and system for the relative poverty period and reduce the risk of returning to poverty through multiple means, namely, industrial poverty alleviation, employment poverty alleviation, and education poverty alleviation. 
Secondly, the regulatory authorities should raise the requirements on the degree of APA information disclosure in the capital market. A sound APA information disclosure system helps to shape a good external image of listed enterprises and enables market investors to clearly understand the APA trend of listed enterprises. Hence, the regulatory authorities should strictly regulate existing APA information disclosure conditions and update the system of information disclosure by adding disclosure forms and contents, turning passive disclosure to proactive disclosure.

Thirdly, the government should provide a better external environment for enterprises engaging in APA. The government should adopt a series of policies and measures to encourage and guide enterprises to actively participate in APA, mitigate their stress and burden of APA engagement, and enhance the initiative and autonomy of enterprises, forming a benign interaction between APA and corporate development. To ensure the long-term stable APA involvement of enterprises, the government departments could roll out favorable policies on taxation, financing, and industrial development and provide the enterprises engaging in APA with a more convenient business environment.

\section{Data Availability}

The data used to support the findings of this study are available from the corresponding author upon request.

\section{Conflicts of Interest}

The authors declare that they have no conflicts of interest.

\section{Acknowledgments}

The authors acknowledge funding from the National Social Science Fund Youth Project (20cgl013).

\section{References}

[1] S. Jayech, "The contagion channels of July-August-2011 stock market crash: a DAG-copula based approach," European Journal of Operational Research, vol. 249, no. 2, pp. 631-646, 2016.

[2] L. Jin and S. Myers, "R2 around the world: new theory and new tests々," Journal of Financial Economics, vol. 79, no. 2, pp. 257-292, 2006.

[3] S. P. Kothari, S. Shu, and P. D. Wysocki, "Do managers withhold bad news?" Journal of Accounting Research, vol. 47, no. 1, pp. 241-276, 2009.

[4] J. L. Callen and X. Fang, "Crash risk and the auditor-client relationship," Contemporary Accounting Research, vol. 34, no. 3, pp. 1715-1750, 2017.

[5] R. Zhao, "Quantifying the correlation of media coverage and stock price crash risk: a panel study from China," Physica A: Statistical Mechanics and Its Applications, vol. 537, no. 1, Article ID 122378, 2020.

[6] Y. Kim, H. Li, and S. Li, "Corporate social responsibility and stock price crash risk," Journal of Banking \& Finance, vol. 43, no. 6, pp. 1-13, 2014.

[7] M.-T. Lee, "Corporate social responsibility and stock price crash risk," Managerial Finance, vol. 42, no. 10, pp. 963-979, 2016.
[8] S. Yao, J. Wang, and F. Wang, "Theoretical mechanism and literature analysis of $\mathrm{Xi}$ Jinping's important opinion on poverty alleviation in China's new era," Modern Economic Science, vol. 41, no. 1, pp. 7-19, 2019.

[9] S. Du, H. Shi, and Y. Zhang, "Research on the influencing factors of the precise poverty alleviation behavior of listed companies in China: based on the perspective of social responsibility," Public Finance Research, vol. 30, no. 2, pp. 104-115, 2019.

[10] Y. Yi, B. Xie, L. Zhou, and Y. Wei, "Does CSR affect the cost of equity capital: empirical evidence from the targeted poverty alleviation of listed companies in China," PLoS One, vol. 15, no. 2, Article ID e0227952, 2020.

[11] F. Wang, Y. Tao, and J. Ni, "Research on investment efficiency and performance of listed companies under the background of precision poverty alleviation: based on samples of private enterprises," China Soft Science, vol. 35, no. 6, pp. 122-135, 2020.

[12] C. Ren and Z. Wang, "Research on the influencing factors of enterprises intervening in targeted poverty alleviation: an empirical analysis from attention perspective," Soft Science, vol. 34, no. 6, pp. 72-78, 2020.

[13] Y. Chang, W. He, and J. Wang, "Government initiated corporate social responsibility activities: evidence from a poverty alleviation campaign in China," Journal of Business Ethics, vol. 173, no. 4, pp. 661-685, 2021.

[14] Y. Kim, M. S. Park, and B. Wier, "Is earnings quality associated with corporate social responsibility?" The Accounting Review, vol. 87, no. 3, pp. 761-796, 2012.

[15] A. Lizzeri, "Information revelation and certification intermediaries," Journal of Economics, vol. 30, no. 5, pp. 214-311, 1990.

[16] R. L. Watts, "Conservatism in accounting Part I: explanations and implications," Accounting Horizons, vol. 17, no. 3, pp. 207-221, 2003.

[17] R. Ball, S. Jayaraman, and L. Shivakumar, "Audited financial reporting and voluntary disclosure as complements: a test of the confirmation hypothesis," Journal of Accounting and Economics, vol. 53, no. 1, pp. 136-166, 2012.

[18] X. Quan and H. Xiao, "Study on the effect of corporate social responsibility disclosure on stock price crash risk: based on mediation mechanism of accounting conservatism," China Soft Science, vol. 31, no. 6, pp. 80-97, 2016.

[19] D. O. Neubaum and S. A. Zahra, "Institutional ownership and corporate social performance: the moderating effects of investment horizon, activism, and coordination," Journal of Management, vol. 32, no. 1, pp. 108-131, 2006.

[20] K. V. Lins, H. Servaes, and A. Tamayo, "Social capital, trust, and firm performance: the value of corporate social responsibility during the financial crisis," The Journal of Finance, vol. 72, no. 4, pp. 1785-1824, 2017.

[21] P. C. Godfrey, C. B. Merrill, and J. M. Hansen, "The relationship between corporate social responsibility and shareholder value: an empirical test of the risk management hypothesis," Strategic Management Journal, vol. 30, no. 4, pp. 425-445, 2009.

[22] A. P. Hutton, A. J. Marcus, and H. Tehranian, "Opaque financial reports, R2, and crash risks," Journal of Financial Economics, vol. 94, no. 1, pp. 67-86, 2009.

[23] N. Xu, X. Li, Q. Yuan, and K. C. Chan, "Excess perks and stock price crash risk: evidence from China," Journal of Corporate Finance, vol. 25, no. 4, pp. 419-434, 2014. 
[24] J. Susnjara, T. Ngo, and S. Jory, "Stock mergers and acquirers' subsequent stock price crash risk," Review of Quantitative Finance and Accounting, vol. 54, no. 1, pp. 359-387, 2020.

[25] P. M. Dechow, R. Sloan, and A. P. Sweeney, "Detecting earnings management," Accounting Review, vol. 70, no. 2, pp. 193-225, 1995.

[26] B. Deng, C. Tao, and L. Ji, "Firms' targeted poverty alleviation and the ease of financial constraints," Journal of Finance and Economics, vol. 46, no. 12, pp. 138-151, 2020.

[27] J. Dong, J. Pang, X. Li, and Z. Dong, "Exploring the relationship between institutional investor holdings and stock price crash risk: a test based on market variables," Journal of Management Sciences in China, vol. 23, no. 3, pp. 73-88, 2020.

[28] S. Liang, C. Xu, and R. Wang, "Board faultlines and stock price crash risk," China Industrial Economics, vol. 38, no. 3, pp. 155-173, 2020.

[29] H. Chowdhury, R. Faff, and K. Hoang, "Using abnormal analyst coverage to unlock new evidence on stock price crash risk," Accounting and Finance, vol. 61, no. S1, pp. 1557-1588, 2020.

[30] R. M. Bushman, J. D. Piotroski, and A. J. Smith, "What determines corporate transparency?" Journal of Accounting Research, vol. 42, no. 2, pp. 207-252, 2004.

[31] D. C. Hambrick and P. A. Mason, "Upper echelons: the organization as a reflection of its top managers," Academy of Management Review, vol. 9, no. 2, pp. 193-206, 1984.

[32] U. Malmendier, G. Tate, and J. Yan, "Overconfidence and early-life experiences: the effect of managerial traits on corporate financial policies," The Journal of Finance, vol. 66, no. 5, pp. 1687-1733, 2011.

[33] N. Xu and Z. Li, "CEOs' poverty experience and corporate philanthropy," Economic Research Journal, vol. 51, no. 12, pp. 133-146, 2016.

[34] B. Cheng, Y. Xuan, and F. Pan, "The signaling effect of party organization governance in SOEs: analysis based on auditor choice," Journal of Finance and Economics, vol. 43, no. 3, pp. 69-80, 2017. 